\title{
Comparative Study on Newcastle Disease and Infectious Bursal Disease in Chicken Submitted to Upazilla Veterinary Hospital, Bogra Sadar, Bangladesh
}

\author{
Arup Sen ${ }^{1 *}$, Abu Torab ${ }^{1}$, Abdus Salam SM², Bhubon Halder ${ }^{2}$ and Alauddin MD $^{2}$ \\ ${ }^{1}$ Department of Microbiology and Veterinary Public Health, Chittagong Veterinary and Animal Sciences University, Chittagong, Khulshi, Bangladesh \\ ${ }^{2}$ Faculty of Veterinary Medicine (FVM), Chittagong Veterinary and Animal Sciences University, Chittagong, Khulshi, Bangladesh
}

\begin{abstract}
The study was conducted on 123 chickens submitted to Upazila Veterinary Hospital, Bogra Sadar for the detection of Newcastle disease (ND) and Infectious Bursal disease (IBD) during the period of 9th February to 8th April 2017. On the basis of history and postmortem examination findings, the prevalence of ND and IBD was $8.13 \%$ and $23.58 \%$, respectively. The morbidity was $6.19 \%$ and $3.69 \%$ in ND and IBD, respectively. The mortality of ND and IBD was $4.00 \%$ and $2.009 \%$, respectively. The main pathological lesions observed in this study were pinpointed hemorrhage in the proventricular gland, thickness of proventriculus wall, hemorrhage in the duodenum in case of ND and hemorrhages on thigh and breast muscles; inflamed, edematous, hyperemic and hemorrhagic bursa of Fabricious in IBD. The study also showed that the chickens of more than 30 days old and chickens within 15-30 days old were highly susceptible to ND $(27 \%)$ and IBD $(44 \%)$, respectively.
\end{abstract}

Keywords: Chicken; Newcastle disease; Infectious bursal disease; Prevalence; Bogra Sadar

\section{Introduction}

The economy of Bangladesh is agro based. About $21.77 \%$ of Gross Domestic products (GDP) come from agriculture sector of which livestock alone shares $7.23 \%$ [1]. Within the livestock sector poultry has the highest contribution to GDP. The poultry industry is an important part of agriculture in our country. Poultry farming is gradually taking the shape of a large industry, and it is now one of the intensive forms of agri-business in our country. In order to achieve the Millennium Development Goal (MDG), Bangladesh is committed to developing the poultry sector. The total poultry population, both backyard, and commercial accounts to approximately 246 million, providing 5400 million pieces of eggs annually and nearly $15 \%$ of total animal protein This sector employs about 5 million people of the country and has experienced a long-term growth rate of about $4.5 \%$, which is one of the highest in the economy and is believed to have accomplished a silent revolution in Bangladesh [2]. Some diseases create problems to run poultry farming profitably, such as Newcastle disease, Infectious bursal disease, Colibacillosis, Salmonellosis, Mycoplasmosis, Coccidiosis, Necrotic enteritis etc. Among these, Newcastle disease and Infectious Bursal disease are the threat for both commercial poultry and backyard poultry farming.

Newcastle disease (ND) is indicated as the most significant viral disease of poultry in the world together with developing countries [3]. In Africa and Asia ND is a major constraint to the development of both industrial and village poultry production. NDV infections of poultry range from latent to rapidly fatal depending upon the pathotype of virus involved [4]. Chicks from immunized parents possess a high level of maternally derived antibodies (MDA) which protect them against virulent and vaccine viruses $[5,6]$. The outbreak of diseases in Bangladesh causes about 30\% mortality of chickens [7]. Among them, infectious bursal disease (IBD) is one of the major viral diseases which cause $80 \%$ mortality in field outbreak [8].

The etiological agent of IBD, infectious bursal disease virus (IBDV), is a non-enveloped virus, belonging to the family Birnaviridae, with a bisegmented double-stranded RNA genome [9]. Since 1992, the poultry farms of Bangladesh have been experiencing the outbreaks of a disease resembling acute IBD. Swollen bursa and sometimes atrophied bursa, edematous and hyperemic bursa, gelatinous yellowish transudate covering the serosal surface and swollen kidney were observed in post-mortem examinations. Hemorrhage and areas of necrosis may be present in more severe cases of IBD. Hemorrhage may be seen in the thigh and pectoral muscles [10-14]. IBD causes significant mortality in chickens in Bangladesh. The disease is in both private and government farms in the country. IBD is frequently reported even from vaccinated flocks. Sometimes farmers are confused and cannot suspect clinically on their own the occurrences of ND and IBD and the prevalence estimates of these diseases at a particular upazilla level are not clearly known to them as well.

\section{Materials and Methods}

The study was conducted at Upazilla Veterinary Hospital, Bogra (UVH, B) Sadar, Bogra district, Bangladesh. The duration of the study was the period of 8 weeks, starting from $9^{\text {th }}$ February 2017 to $8^{\text {th }}$ April 2017. A total of 123 birds were examined which were submitted to UVH, $\mathrm{B}$ from different commercial farms. Birds were examined postmortem at the UVH, B. ND and IBD on the reported farms were suspected based on the farmers' perceptions on clinical histories of diseases as received by taking direct interviews with them which were recorded on

*Corresponding author: Dr. Arup Sen, DVM, MS, Department of Microbiology and Veterinary Public Health, Chittagong Veterinary and Animal Sciences University, Chittagong, Khulshi-4225, Bangladesh, Tel: +8801812716471; E-mail: arup09dvm@gmail.com

Received June 08, 2017; Accepted June 23, 2017; Published June 26, 2017

Citation: Sen A, Torab A, Salam SMA, Halder B, Alauddin MD (2017) Comparative Study on Newcastle Disease and Infectious Bursal Disease in Chicken Submitted to Upazilla Veterinary Hospital, Bogra Sadar, Bangladesh. J Vet Sci Technol 8: 455 doi: 10.4172/2157-7579.1000455

Copyright: (C) 2017 Sen A, et al. This is an open-access article distributed under the terms of the Creative Commons Attribution License, which permits unrestricted use, distribution, and reproduction in any medium, provided the original author and source are credited. 
questionnaires. Some epidemiological information, such as bio-security management of a farm, vaccination, mortality and feed/water source were also recorded on it.

\section{Case definition}

Most of the time sick birds or dead birds brought to the Veterinary Hospital, examined first, history was taken from the farmers and finally postmortem examination was done. The bird which represent swollen or atrophied Bursa, hemorrhage /edematous fluid in bursa, hemorrhage on thigh muscles and breast muscles etc found on the postmortem examination were considered as case of IBD and ND is considered if pinpoint hemorrhage at the tip of the proventicular glands, hemorrhagic/diptheric ulcers on the intestine and caecal tonsils were found on post-mortem. The clinical signs and post-mortem findings of other concomitant infections with ND and IBD were recorded. Post-mortems examinations were carried out and the different disease conditions of the birds were examined and tentative diagnoses were made as described by Calnek [15]. The clinical signs as seen or described by the owners and postmortem examination findings based on which ND and IBD and other diseases were diagnosed. The prevalence (\%) of $\mathrm{ND}$ or IBD in the birds examined was calculated on the following formula:

$$
\text { Prevalence }=\frac{\text { Total number of infected birds }}{\text { Total number of birds }} \times 100
$$

\section{Data analysis}

All data were entered into a spreadsheet program. Data management and analysis were performed using ANOVA Test: Single Factor using Microsoft Excel 2007. ANOVA Test: Single Factor done for the explanatory variables (Flock size, Age groups, Vaccination) and those having $P$-value $\leq 0.05$ were considered significant.

\section{Results}

In the UVH, B during study period 123 chicken was investigated of which 10 were found positive ND and 29 for IBD. The cardinal post mortem examination findings, especially lesions located into the proventriculus and Bursa of Fabricious based on which ND and IBD were diagnosed. The prevalence estimates of ND by type of birds, age groups, flock sizes and status of ND-vaccination are summarized in Table 1.

Of the total chickens investigated in the study, $8 \%$ were positive for ND. The prevalence (\%) of ND in Sonali chickens was $14 \%$, significantly higher in Sonali chickens compared to broiler ones $(\mathrm{P}<0.05)$. Compared with young ones the prevalence of ND was higher in chickens belonging to the age group $>30$ days $(\mathrm{P}<0.05)$. Surprisingly, ND was evenly distributed in ND-vaccinated and non-vaccinated chickens.

The prevalence estimates of IBD in chickens by type of birds, age, flock size and IBD-vaccination are presented in Table 2 . The prevalence of IBD in chicks of 15-30 days' group was $44 \%$, significantly higher than other age groups $(\mathrm{p}<0.05)$. Surprisingly, IBD was $29 \%$ in vaccinated chicks which are significantly higher than non-vaccinated ones $(\mathrm{P}<0.05)$. Table 3 is presented with the overall farm-based morbidity and mortality in chickens based on the available data. The overall farm-based mortality attributable to ND and IBD were $4 \%$ and $2 \%$, respectively.

\section{Discussion}

About $8 \%$ of the chickens investigated were diagnosed positive with ND which was similar to the findings of Beach, Banerjee et al. and Alexander [16-18]. Most commonly observed postmortem lesions were pinpoint hemorrhages at the tip of proventricular glands, hemorrhagic ulcers in the intestinal wall and caecal tonsils, petechial hemorrhage in the colon, hemorrhagic lungs, tracheitis with congestion and catarrhal exudates. These findings corroborate with the findings of Kotani et al., Crespo et al., Talha et al. and Pazhanivel et al. [19-22]. The prevalence of ND observed in the study is, however, lower than the reports of Biswas et al. on chickens including Sonali reared under backyard system in Bangladesh [23,24]. A higher prevalence of ND in Sonali chickens, as observed in the study might be relating to weaker biosecurity for them compared to a better system of rearing for broiler chicks. The even distribution of ND in vaccinated and non-vaccinated birds should raise a question on the quality of vaccine used or its preservation and time of vaccination. This high prevalence of IBD found in this study is in accordance with the observation of Islam et al. who reported the proportion to be $24 \%$ in broiler chickens in Sylhet region [25]. However, there are reports in the other parts of the country which demonstrated the occurrence of this disease is lower than the present findings [21,26]. The highest prevalence (44\%) of IBD was found in the group of $15-30$ days birds and lowest (0\%) in the group of 0-15 days birds. Lukert and Saif reported that clinically infectious bursal disease mostly occurs in the young chicken between 3-6 weeks of age, but the disease has also been reported to occur between 9 days to 20 weeks of age [27]. Rahman et al. found that the broilers of four weeks of age were highly susceptible to IBD (55\%), whereas in third week $12.5 \%$ and in the fifth week $32.5 \%$ chicks were infected with IBDV and the broilers of two weeks of age were not affected with the virus [28]. Khan et al. reported that IBD affected birds were four weeks old conclusively [29]. Rajaonarison et al. showed that the birds of three to five weeks of old were most susceptible to IBD [30]. Wyeth et al. carried out studies IBDV in Great Britain and reported that IBDV can infect some chicks as young as fifteen days old [31]. No bird was found affected up to fifteen days. In this study, the outbreak of IBD in vaccinated flocks was significantly higher $(\mathrm{P}<0.05)$ which has also been described previously by Anku in Southern Ghana, Islam and Samad in Bangladesh and Jindal et al. in India $[11,25,32]$. They opined that factors like improper vaccination, poor biosecurity measures and the existence of very virulent strains of IBD virus contributed to the occurrence of IBD in the vaccinated flocks. The mortality rate of IBD (2\%) in this study was similar to a previous report of Jindal et al. [32]. Age of the bird had a significant relationship on the prevalence and mortality of the disease. Mortality due to IBD in

\begin{tabular}{|c|c|c|c|c|}
\hline Variable & $\mathbf{N}$ & $\begin{array}{l}\text { Prevalence\% } \\
\text { (No. positive) }\end{array}$ & $95 \% \mathrm{Cl}$ & $P$ value \\
\hline \multirow{2}{*}{ Type of bird } & Sonali (63) & $14 \%(9)$ & $6-25$ & \multirow{2}{*}{0.0258} \\
\hline & Broiler (60) & $2 \%(1)$ & $0.04-8$ & \\
\hline \multirow{3}{*}{ Age } & <15 days (35) & $0 \%(0)$ & $0-10$ & \multirow{3}{*}{0.0008} \\
\hline & $15-30$ days (66) & $6 \%(4)$ & $32-57$ & \\
\hline & $>30$ days $(22)$ & $27 \%(6)$ & $0-15$ & \\
\hline \multirow{4}{*}{ Flock size } & $<1000$ birds $(36)$ & $0 \%(0)$ & $0-9$ & \multirow{4}{*}{0.0738} \\
\hline & $\begin{array}{c}1000-<2000 \text { birds } \\
(45)\end{array}$ & $16 \%(7)$ & $6-29$ & \\
\hline & $\begin{array}{c}2000-<4000 \text { birds } \\
(34)\end{array}$ & $6 \%(2)$ & $0.72-19$ & \\
\hline & $\geq 4000$ birds $(8)$ & $12 \%(1)$ & $0.32-52$ & \\
\hline \multirow{2}{*}{ ND vaccinated } & Yes (107) & $8 \%(9)$ & $3-15$ & \multirow{2}{*}{0.8451} \\
\hline & No (16) & $6 \%(1)$ & $15-64$ & \\
\hline Total & 123 & $8.13 \%$ & $3-14$ & \\
\hline
\end{tabular}

Table 1: Prevalence estimates of ND by type of birds, age, flock size and NDvaccination in the investigated chickens. 
Citation: Sen A, Torab A, Salam SMA, Halder B, Alauddin MD (2017) Comparative Study on Newcastle Disease and Infectious Bursal Disease in Chicken Submitted to Upazilla Veterinary Hospital, Bogra Sadar, Bangladesh. J Vet Sci Technol 8: 455. doi: 10.4172/2157-7579.1000455

Page 3 of 4

\begin{tabular}{|c|c|c|c|}
\hline \multirow{2}{*}{ Variable } & $\mathbf{N}$ & $\begin{array}{c}\text { Prevalence\% } \\
\text { (No. positive) }\end{array}$ & 95\% Cl \\
\hline \multirow{2}{*}{ Type of bird } & Sonali (63) & $22 \%(14)$ & $12-34$ \\
\hline \multirow{2}{*}{ Age } & Broiler (60) & $25 \%(15)$ & $15-38$ \\
\hline & $<15$ days (35) & $0 \%(0)$ & $0-10$ \\
\hline \multirow{3}{*}{ Flock size } & $15-30$ days (66) & $44 \%(29)$ & $32-57$ \\
\hline & $>30$ days (22) & $0 \%(0)$ & $0-15$ \\
\hline & $<1000$ birds (36) & $22 \%(8)$ & $10-39$ \\
\hline \multirow{2}{*}{ IBD vaccination } & $1000-<2000$ birds (45) & $13 \%(6)$ & $17-27$ \\
\hline Total & $2000-<4000$ birds (34) & $32 \%(11)$ & $15-84$ \\
\hline
\end{tabular}

Table 2: Prevalence estimates of IBD in chickens by type of birds, age, flock size and IBD-vaccination in the investigated chickens.

\begin{tabular}{|c|c|c|c|c|}
\hline \multirow{2}{*}{ Farm No. } & \multicolumn{2}{|c|}{ Morbidity (\%) } & \multicolumn{2}{|c|}{ Mortality (\%) } \\
\hline & ND & IBD & ND & IBD \\
\hline 1 & & 0.84 & & 0.24 \\
\hline 2 & & 2 & & 1 \\
\hline 3 & & 3.2 & & 0.2 \\
\hline 4 & & 0.05 & & 0.05 \\
\hline 5 & & 0.5 & & 0 \\
\hline 6 & 3.1 & & 0.1 & \\
\hline 7 & & 1.55 & & 0.67 \\
\hline 8 & & 3.18 & & 2.92 \\
\hline 9 & & 1.37 & & 1.25 \\
\hline 10 & & 6.4 & & 0.4 \\
\hline 11 & & 4.16 & & 1.67 \\
\hline 12 & & 0.72 & & 0.73 \\
\hline 13 & 17.5 & & 16.66 & \\
\hline 14 & & 8 & & 6 \\
\hline 15 & & 8 & & 7.5 \\
\hline 16 & & 1.6 & & 0.8 \\
\hline 17 & & 0.85 & & 0.14 \\
\hline 18 & 1.63 & & 1.17 & \\
\hline 19 & 17.14 & & 14.28 & \\
\hline 20 & 0.46 & & 0.2 & \\
\hline 21 & 1.1 & & 0.5 & \\
\hline 22 & 4 & & 2.5 & \\
\hline 23 & & 6.25 & & 3.13 \\
\hline 24 & & 7.5 & & 2.5 \\
\hline 25 & & 1.2 & & 0.8 \\
\hline 26 & & 5.9 & & 4.09 \\
\hline 27 & & 1 & & 0.6 \\
\hline 28 & & 15.22 & & 10.87 \\
\hline 29 & & 1.37 & & 0.13 \\
\hline 30 & 10.27 & & 1.18 & \\
\hline 31 & 4 & & 1 & \\
\hline 32 & & 4.09 & & 1.82 \\
\hline 33 & 2.72 & & 2.27 & \\
\hline 34 & & 12 & & 8 \\
\hline 35 & & 4.8 & & 0.35 \\
\hline 36 & & 2.25 & & 1.5 \\
\hline 37 & & 1.2 & & 0.4 \\
\hline 38 & & 0.33 & & 0.2 \\
\hline 39 & & 1.33 & & 0.33 \\
\hline Average & 6.19 & 3.69 & 4.00 & 2.00 \\
\hline
\end{tabular}

Table 3: Comparison of morbidity and mortality in case of ND and IBD, on the basis of farms where the birds were from. 
Citation: Sen A, Torab A, Salam SMA, Halder B, Alauddin MD (2017) Comparative Study on Newcastle Disease and Infectious Bursal Disease in Chicken Submitted to Upazilla Veterinary Hospital, Bogra Sadar, Bangladesh. J Vet Sci Technol 8: 455. doi: 10.4172/2157-7579.1000455

chicks was significantly higher in vaccinated chicks, an agreement with the findings of Shil et al. [33]. The prevalence, mortality, and morbidity of IBD were $7.75 \%, 6.38 \%$, and $1.35 \%$, respectively. Khan et al.; Sami and Baruah recorded 55 outbreaks of IBD in broiler flocks from 1993-95 with mortality ranging from $0.9-25.7 \%[30,34]$

\section{Conclusion}

The important postmortem findings in ND and IBD cases during postmortem examinations might be observed in the proventriculus and the Bursa of Fabricious, respectively. The prevalence of ND in the UVH, B might be $8 \%$. The prevalence (\%) of ND in Sonali chickens was $14 \%$, which is significantly higher than broiler chicks. ND was also higher in chickens more than one month of age than younger birds. The distribution of ND was even in ND-vaccinated and non-vaccinated chickens. The prevalence of IBD in chicks of 15-30 days' group was much higher than the younger chicks. IBD was also much higher in vaccinated chicks. Farm-based mortality attributable to ND and IBD appears to be $4 \%$ and $2 \%$, respectively.

\section{Conflicts of Interest}

The authors declare no conflicts of interest.

\section{Acknowledgements}

The author expresses his deepest sense of gratitude, and respect to his honorable teacher and internship supervisor, Professor Dr. Paritosh Kumar Biswas, Department of Microbiology and Veterinary Public Health, Chittagong Veterinary and Animal Sciences University for his scholastic guidance, sympathetic supervision, valuable advice, continuous inspiration, radical investigation and constructive criticism in all phases of study.

\section{References}

1. Bangladesh Bureau of Statistics. Livestock Survey in 2005-2006.

2. BLRI (2008) A Study on Highly Pathogenic Avian Influenza in Bangladesh Bangladesh Livestock Research Institute, Savar, Dhaka.

3. Spradbrow PB (1997) Policy framework for smallholder rural poultry development. In: Proceedings of International Workshop on Sustainable Poultry Production in Africa held in Addis Ababa, Ethiopia. pp: 30-39.

4. Alexander DJ (2003) Newcastle disease, other Paramyxoviruses and Pneumovirus Infections. In: Saif YM, Barnes HJ, Glossons GR, Fadly MA, McDougald DJ, Swayne DE (eds.), Diseases of Poultry, lowa State Press, AMES, pp: 63-100.

5. Allan WH, Lancaster JA, Toth B (1978) Newcastle disease vaccines: their production and use. FAO Animal Production and Health Series. FAO, Rome.

6. Rahman MM, Bari ASM, Giusuddin M, Islam MR, Alam J, et al. (2002) Evaluation of maternal and humoral immunity against Newcastle disease virus in chicken. Int J Poult Sci 1: 161-163.

7. Ali MJ (1994) Current status of veterinary biologics production in Bangladesh and their quality control proceeding of BSVER symposium held on July 28, 1994 at NIPSOM auditorium, Mohakhali, Dhaka, Bangladesh.

8. Chowdhury EH, Rahman IA (1996) Observation of outbreaks and subsequen control of infectious bursal disease in the central poultry farm in Bangladesh. Bangladesh Vet J 30: 13-17.

9. Kibenge FSB, Dhillon AS, Russel RG (1988) Biochemistry and immunology of infectious bursal disease virus. J Gen Virol 69: 1757-1775.

10. Butcher GD, Miles RD (2001) Infectious bursal disease (Gumboro) in commercial broilers. University of Florida.

11. Anku GG (2003) Gumboro hampers efforts to improve nutrition of Ghana's growing population. Poult Int 12: 32-36.

12. Rodriguez-Chavez R, Issac WS, Cloud S, Sandra MD (2002) Characterization of antigenic, immunogenic and pathogenic variant of infectious bursal disease virus due to propagation in different host systems (Bursa, embryo and cell culture). Avian Pathol 31: 475-492.
13. Saif YM, Abdel-Amin GA (2001) Pathogenecity of cell culture derived and bursa derived infectious bursal disease viruses in specific pathogen free chickens. Avian Dis 45: 844-852.

14. Dybing K, Jackwood DJ (1998) Antigenic and Immunogenic properties of baculovirus-expressed infectious bursal disease viral proteins. Avian Dis 42 : 80-91.

15. Calnek BW (1997) Infectious bursal disease. In: Lukert PD, Saif YM (eds.), 10th edn. International Publishers Limited, pp: 721-733.

16. Beach JR (1942) Avian Pneumoencephalitis. Proceeding of annual meeting in US livestock sanitary association, Springer, Milan, Berlin, Heidelberg, New York.

17. Banerjee M, Reed W, Fitzgerald SD, Paniger B (1994) Neurotropic Velogenic Newcastle disease incormorants in Michigan: Pathology and virus characterization. Avian Dis 38: 873-878.

18. Alexnader DJ (1997) Newcastle disease and other avian paramyxoviridae infections. In: Calnek BW, et al. (eds.), Diseases of Poultry. 10th edn. Ames. lowa State University Press, pp: 541-569.

19. Kotani T, Ddagiri Y, Nakamura J, Horiuchi T (1987) Pathological changes of tracheal mucosa in chickens infected with lentogenic NDV. Avian Dis 31: 491-497.

20. Crespo R, Shivaprasad HL, Woolcock PR, Chin RP, Davidson-York D, et al. (1999) Exotic Newcastle disease in a game chicken flock. Avian Dis 43: 349-355.

21. Talha AFSM, Hossain MM, Chowdury EH, Bari ASM, Islam MR, et al. (2010) Poultry Diseases Occurring in Mymensingh District of Bangladesh. Bangladesh Vet J 18: 20-23.

22. Pazhanivel N, Balsubramaniam GA, George VT, Mohan B (2002) Study of natural outbreak of Newcastle disease in and around Namakkal. Indian Vet $J$ 79: 293-294.

23. Biswas PK, Biswas D, Ahmed S, Rahman A, Debnath NC (2005) A longitudina study of the incidence of major endemic and epidemic diseases affecting semiscavenging chickens reared under the Participatory Livestock Development Project areas in Bangladesh. Avian Pathol 34: 303-312.

24. Biswas PK, Uddin GM, Barua H, Roy K, Biswas D, et al. (2006) Causes of loss of Sonali chickens on smallholder households in Bangladesh. Prev Vet Med 76: 185-195

25. Islam MT, Samad MA (2003) Outbreak of infectious bursal diseases in vaccinated and unvaccinated commercial cockerel farms in Bangladesh. Bangladesh J Vet Med 1: 21-24

26. Giasuddin M, Sil BK, Alam J, Koike I, Islam MR, et al. (2002) Prevalence of Poultry Diseases in Bangladesh. Indian J Poult Sci 40: 99-101.

27. Lukert PD, Saif YM (1997) Infectious bursal disease: Disease of poultry. 9th edn. Wolfe Publishing Limited, pp: 684-663.

28. Rahman MS, Islam MS, Rahman MT, Parvez NH, Rahman MM (2010) Analysis of prevalence of infectious Bursal disease in broiler flocks in Dinajpur. Int $J$ Sustain Crop Prod 5: 15-18.

29. Khan RW, Khan FA, Farid K, Khan I, Tariq M (2009) Prevalence of Infectious Bursal Disease in Broiler in District Peshawar. ARPN J Agric Biologic Sci 4: 1-5.

30. Rajaonarison JJ, Rakotonindrina E, Rakotondramary SM, Razafimanjary S (2006) Gumboro Disease (Infectious bursitis) in Madagascar. Rev Elev Med Vet Pays Trop 47: 15-17.

31. Wyeth PJ, Chettle NJ, Mohepat AR (2003) Infectious bursal disease in Great Britain. Vet Rec 130: 30-32.

32. Jindal N, Mahajan NK, Mittal D, Gupta SL, Khokhar RS (2004) Some epidemiological studies on infectious bursal disease in broiler chickens in parts of Haryana, India. Int J Poult Sci 3: 478-482.

33. Shil GC, Ehsam MA, Rahmn MS, Anower AKMM, Ismal MR (2003) Diseases associated with mortality and pathological changes in cockerel birds. Bangladesh $J$ Vet Med 1: 33-38

34. Sami W, Baruah GK (1997) Incidence of infectious bursal disease in broilers in Assam. Indian J Vet Pathol 21: 67-68. 